\title{
Editoríal.
}

\section{THE PSYCHOLOGICAL FACTOR OF ALCOHOL.}

THE fact alone that in all countries mankind has spontaneously indulged in fermented liquors should lead us to presume that such a trend must have some deep-seated origin. It is, therefore, to be deplored that hitherto the relationship of alcohol to society and the individual has largely been treated superficially, which accounts for the meagre enlightenment thrown upon the problems involving the community, and the highly inadequate understanding of those prevalent mental abnormalities which have an evident connection with alcoholic indulgence and with which psychiatrists are more especially familiar. A cursory investigation only will be sufficient to reveal that, in the main, mankind does not imbibe alcohol for the purpose of quenching thirst or because it specially gratifies his palate, but for some less evident reason. It is true that such an assertion would not seem to hold good if we relied upon the individual's statement as to the meaning of his impulse; but on such a theme man rationalizes freely, and it is not difficult to see that, at any rate to a great extent, he is unconsciously motivated. Tradition and habit have their values, of course, in moulding action; but we are here mainly concerned with the broad contention that in modern civilization alcohol seems to be a necessary factor to the majority of those constituting society, in that it affords, by means of its psychological effects, a refuge from the mental conflicts which, in our present era, must result from inhibition of instinctive forces and the warring of internal antagonistic tendencies. Modern psychology and recent study of abnormal mental states have thrown much light upon the mechanisms of the mind which operate in the strivings towards adaptation to environment, in the correctness of which lie happiness and mental health.

It is found, too, to be an unfortunate fact that not only do mental conflicts of various types and degrees exist in the majority of us, but that their healthy solution is perhaps only too infrequent, this being due partly to psychopathic soil and partly to a defective insight into the real factors involved. In most instances the fact that any mental conflict exists within us may very likely be only dimly recognized, or not at all. Mankind has found that the taking of alcohol vol. II, -No. 8 . 
acts as a nareotic at the psychological level, and thus, by benumbing the discordant clements, mental equanimity is gained. Thus unconsciously does a large section of the community upkecp a certain mental equilibrium, and we go so far as to say that thereby much so-called 'nervous' illness is held in check or aborted, and that without this aid mental illness might be even more in evidence. Alcoholic drinking, of course, may also be consciously resorted to in times of worry and stress, and with moderate imbibition similar results occur. We should be scientifically correct in saying that in many instances such a refuge in the face of mental strain is a poor type of adaptation; but too frequently it forms the only solution, notwithstanding the dangers that beset such a path. Trotter, in his work on Herd Instinct, confirms our thesis, and points out the psychological necessity of alcohol as a means for securing some way out, for however short a time, of the prison-house of reality.

There is no doubt also that alcohol tends to promote the social instincts, and in this way helps many to a more adequate adaptation to the community in which they exist. The sensation of elation which is commonly experienced after a certain quantity of alcohol is absorbed, though partly due to somatic causes, is also due to the psychological effect, since thereby various social taboos and ethical inhibitions have had their repressing forces lessened, and the individual concurrently feels a greater freedom of his ego and enhancement of personal power. It is seen, then, that alcohol acts upon the psyche in such a way that the more recently acquired adaptational activities are placed in abeyance, with consequent regression to more individualistic thought and action which will differ according to the personality. 'In vino veritas' is thus scientifically true. Sublimation tends to be abrogated, and suppressed and repressed trends are apt to be freed. Psycho-analysts draw attention to the facts that man drinks usually in the company of his fellow-man, that affectionate behaviour is not uncommonly seen among those who are well under alcoholic influence, and from these observations and their analytic findings they state that a latent homosexuality is thus released. Other impulses may be brought into evidence according to the particular mental soil involved. We may deduce from this that the 'no treating' regulation during the war had a definite psychological basis in its tendency to lessen alcoholic consumption.

When impulses averse to the personal ego-ideal are thus liberated, it is not difficult to see how mental conflict may ensue, which may in its turn induce further and continued libations, so that a vicious circle is set up, with chronic alcoholism as a result. 'The drunkard's humour is proverbial. It is a reaction to disguise the reality of his inner life. The conflict may, however, especially in a psychopathic individual, 
be such that the line of least resistance points to a solution by means of a psychoneurosis or psychosis. Alcohol as a refuge has failed, and peace and safety are sought in the flight into disease.

Psychiatrists classify the psychoses arising in connection with alcohol under the heading of 'toxic psychoses', but from what has been said above, we must see that, with the exception of such forms as Korsakow's syndrome, alcoholic dementia, and delirium, there is no evidence pointing to a toxic origin, whereas there is every indication of emotional traumata which the alcohol has in some way only contributed to by release of buried complexes. The prominent symptoms of delusions of jealousy, grandeur, suspicion, and eroticism can be unravelled in the light of mental conflict, and the hallucinations commonly show the impulses which have been dissociated and projected. Added confirmation is found in the absence of physical signs pointing to any organic implication, and also in the fact that similar clinical pictures may be observed where alcohol can w.th certainty be excluded in the history. Cessation of further alcoholic indulgence may bring about the disappearance of the abnormal symptoms through re-adaptation and return of the sublimation which had been destroyed.

A study of the psychological factor of alcohol becomes a subject of great importance, therefore, in the light of modern research, not only to the psychologist and psychiatrist but also to the sociologist and statesman. It seems that in civilization as it exists no good can accrue from prohibition, and that mankind, robbed of this refuge, would perforce fly to others of a less desirable nature. 